\title{
DIABETES CONTROL - THE LEGACY OF A MEMORY
}

\author{
Vijay AP, Chan SP \\ Department of Medicine, University Malaya Medical Centre, Kuala Lumpur
}

\begin{abstract}
:
Achieving and maintaining good glycaemic control remains an important goal in the management of this common and prevalent disorder. Recent evidence from important megatrials, ACCORD, ADVANCE, VADT, UKPDS-10 year follow-up as well as the STENO-2 follow-up study, have cleared doubts concerning the benefits of targeting good glycaemic control. For the first time, we have the reassurance that macrovascular benefits can be realised from good glycaemic control. The legacy effect of prior good glucose control from the UKPDS-10 year follow-up, reinforces the results seen from the DCCT-EDIC (for Type 1 diabetes). The Intervention Phase of the UKPDS revealed benefits for reduction of microvascular complications, while it was only at the end of the Post-Trial Monitoring Phase where significant improvements in both micro and macrovascular outcomes were seen.
\end{abstract}

The other three Trials assessing the effect of glycaemic control on cardiovascular outcomes, although largely negative for CV benefit, give valuable insight towards appropriate patient characteristics for which aggressive glucose control can and should be instituted. Individualising glycaemic targets, which has been the approach that many clinicians have been practising, has received new impetus albeit with clearer details.

Getting to glycaemic goal early in the course of T2DM and Doing to Safely (Avoiding hypoglycaemia) are the key ingredients to successful management. The legacy of the memory of initial good metabolic/glycaemic control is investment in good health with benefits of reductions in both micro and more importantly, macrovascular disease, years later.

Multifactorial interventions that include blood pressure, lipid lowering in addition to glucose control in these individuals with the Metabolic Syndrome result in more immediate beneficial additive effects on cardiovascular outcomes. (JUMMEC 2009; 12(2): 47-56)

KEYWORDS: Cardiovascular disease, clinical trials, diabetic complications, disease duration, macrovascular complications, microvascular complications, risk of hypoglycaemia, Type 2 diabetes, Type 2 diabetes treatment

\section{Introduction}

The challenge facing all clinicians managing people with Type 2 diabetes mellitus (T2DM) is whether achieving and maintaining good/ideal glycaemic control is worthwhile. These efforts were sorely tested when the Action To Control Cardiovascular Risk in Diabetes (ACCORD) Trial was terminated prematurely, in February 2008, after only 3.5 years due to excess sudden deaths in the intensively treated arm.

Intensive control of glucose to glycated haemoglobin ( $\mathrm{HbA1c}$ ) values below $6.5 \%$ has been proven to reduce diabetic microvascular complications (1). The issue of the benefit of intensifying glycaemic control for reduction of macrovascular complications is now more clearly understood.

The past two years have indeed been eventfulwith the reporting from large megatrials. These trials include the following: ACCORD (Action To Control Cardiovascular Risk in Diabetes) (2),

\section{Correspondence:}

Vijay Ananda a/l Paramesvaran

Department of Medicine

Faculty of Medicine, Universiti Malaya

50603 Kuala Lumpur, Malaysia

Email:vananda@gmail.com 
ADVANCE (Action in Diabetes and Vascular Disease: Preterax and Diamicron Modified Release Controlled Evaluation) (3), VADT (Veterans Administration Diabetes Trial) (4) as well as the UK Prospective Diabetes Study (UKPDS) 10 year follow-up data (5). Results from these important trials have informed and changed clinical management of T2DM.

\section{Legacy of a Memory}

The belief in the memory effect of previous good glycaemic control resulting in long-term vascular (both micro and macrovascular) complication reduction was mooted as far back as 2002 from the interim 4 and 8 year results of the DCCT-EDIC (Epidemiology of Diabetes Interventions and Complications) follow-up study. Such was the case even when glycaemic control is no longer 'ideal' or different between intensive and standard glucose control subjects. This belief was further strengthened by the 10 year observational results from the EDIC6 (Figure 1). These results stemmed from the follow-up of patients in the original DCCT trial of Type 1 diabetic patients. At the end of the intervention phase of the DCCT, the patients were observed for another 8 to 10 years during which there was no longer any difference in glycaemic control. It was found that those in the initial Intensive good control arm over the intervention phase continued to reap the benefits of a decreased rate of microvascular and macrovascular complications. Similar results for individuals with T2DM were not available until the reporting of the UKPDS-10 year, post-trial monitoring results in September 2008, which found essentially similar findings as the DCCT-EDIC (5). These findings showed that intensive glucose control over the first 10 years of the life of a person with
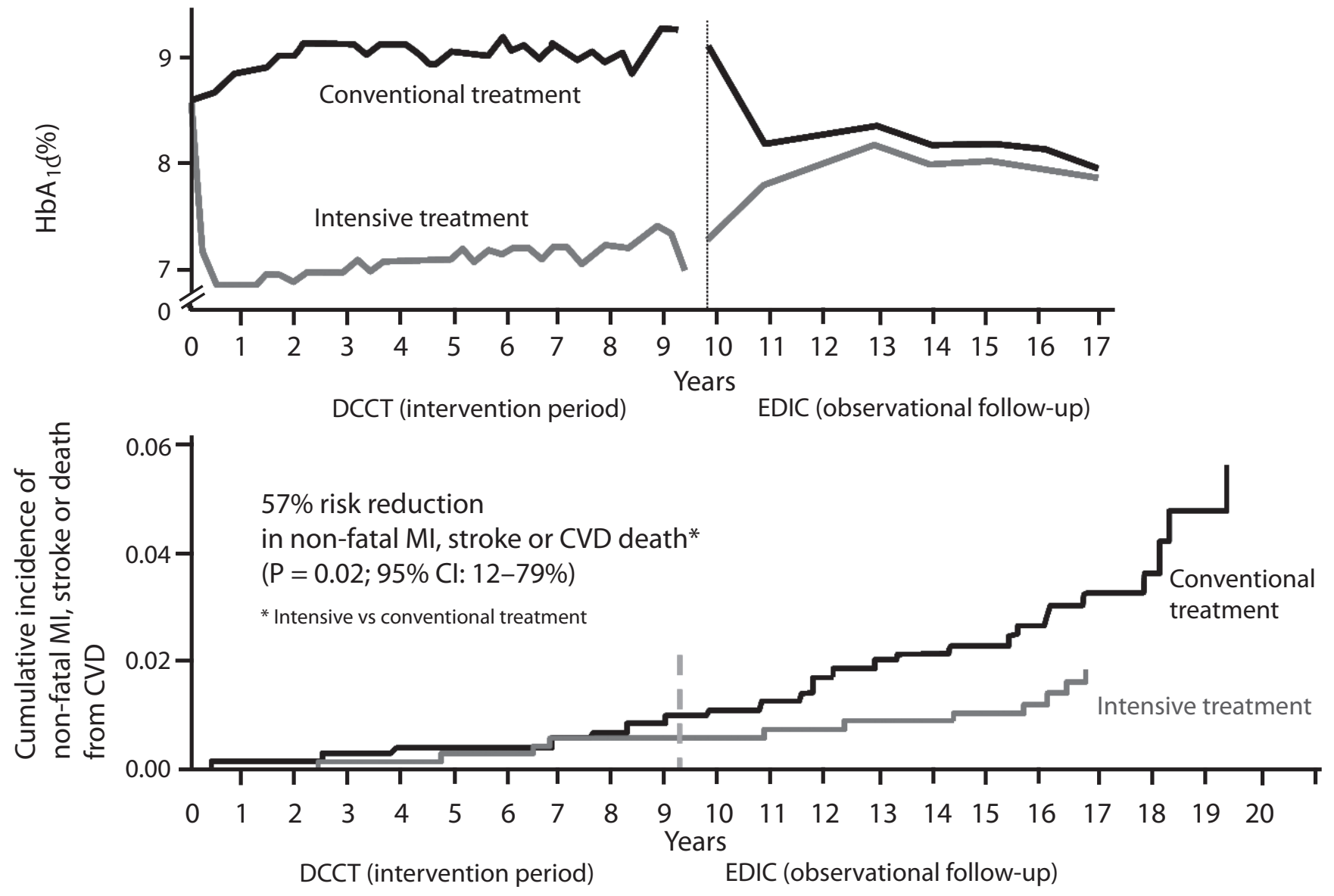

Figure 1: DCCT/EDIC (Type 1 diabetes mellitus): "Memory" of prior Intensive glucose control during the Intervention Phase results in significant reduction of Risk of CV disease during the EDIC (Observation Phase)

Adapted from DCCT. N Engl J Med 1993; 329: 977-986. DCCT/EDIC. JAMA 2002; 287: 2563-2569. DCCT/EDIC. N Engl J Med 2005; 353 : 2643-2653. 


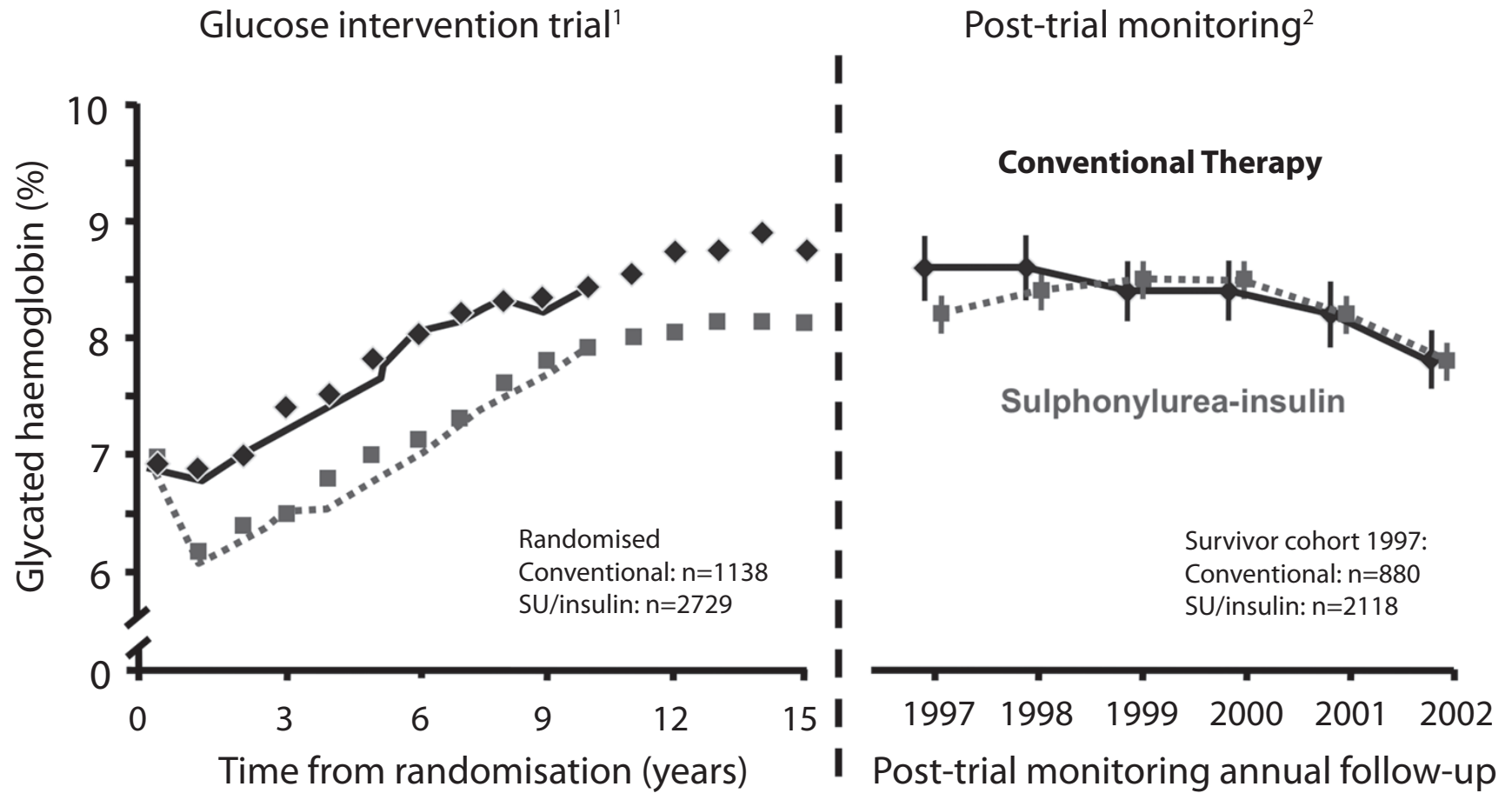

Glucose intervention trial

Patients followed for 10 years:

All patients designated to regimen:

${ }^{1}$ UKPDS Group. Lancet 1998; 352: 837-853.

${ }^{2}$ Holman R, et al. N Engl J Med 2008; 359: 1577-1589.

Figure 2: UKPDS post-trial follow-up: differences in $\mathrm{HbA} 1 \mathrm{c}$ were not maintained after the Intervention Trial ceased

Table 1: UKPDS Post-Trial monitoring - Legacy Effect of Earlier Glucose Control

\begin{tabular}{|c|c|c|c|}
\hline & & $\begin{array}{c}\text { End of } \\
\text { Randomised } \\
\text { Intervention }{ }^{1} \\
1997\end{array}$ & $\begin{array}{c}\text { End of } 10 \text {-year } \\
\text { observational } \\
\text { follow-up } \\
2007\end{array}$ \\
\hline Any diabetes related endpoint & $\begin{array}{c}\text { RRR } \\
\text { p-value }\end{array}$ & $\begin{array}{c}12 \% \\
0.029\end{array}$ & $\begin{array}{c}9 \% \\
0.040\end{array}$ \\
\hline Microvascular Disease & $\begin{array}{c}\text { RRR } \\
\text { p-value }\end{array}$ & $\begin{array}{c}25 \% \\
0.0099\end{array}$ & $\begin{array}{c}24 \% \\
0.001\end{array}$ \\
\hline Myocardial Infarction & $\begin{array}{c}\text { RRR } \\
\text { p-value }\end{array}$ & $\begin{array}{c}16 \% \\
0.052\end{array}$ & $\begin{array}{l}15 \% \\
0.014\end{array}$ \\
\hline All cause Mortality & $\begin{array}{c}\text { RRR } \\
\text { p-value }\end{array}$ & $\begin{array}{c}6 \% \\
0.44\end{array}$ & $\begin{array}{c}13 \% \\
0.007\end{array}$ \\
\hline
\end{tabular}

'UKPDS Group. Lancet 1998; 352: 837-853.

${ }^{2} \mathrm{Holman}$ R, et al. N Engl J Med 2008; 359: 1577-1589. 
Type 2 diabetes brought about in significant benefits, although glucose control was no longer different between previously intensive and standard treatment groups. This led to the coining of a new phrase "legacy effect" of intensive glycaemic control, by the UKPDS group, to leave their "footprint" in the field of diabetology (Figure 2 and Table 1) $(1,5)$.

Further analysis from this landmark study (UKPDS) should therefore be noted. The subjects in the UKPDS were newly diagnosed, without significant cardiovascular complications, were younger (mean age 53 years) and had a lower baseline $\mathrm{HbA1C}$ at time of inclusion into the study. More importantly, the sub-analysis by Stratton et al (7), which reviewed the effect of updated $\mathrm{HbA} 1 \mathrm{c}$ on micro and macrovascular complications. Without a threshold for improvement or reduction of these complications, it should continue to drive glycaemic targets (Figure 3 ).

People with Type 2 diabetes need to be informed that practising good glycaemic control for as long as possible is like investing in their bank for the possibility of a "lean" future-their investment will stand them in good stead when glucose control is more difficult and less ideal with persistence in lower risks of developing the dreaded diabetic vascular complications.

Thus, the legacy of the memory of prior good control is something that clinicians should continually remind themselves in their practice when managing the challenging task of achieving as well as maintaining good/ideal glycaemic control.

\section{Glycaemic control - "Get 'em Early"}

When should good glycaemic control be achieved is the next key question that needs to be answered.

An observation from the UKPDS study population by $S$ Colagiuri et al (8), noted that individuals with lower fasting plasma glucose at diagnosis and recruitment had fewer complications at baseline and fewer adverse clinical outcomes over the course of the trial. This was consistent with the belief that the earlier the detection and diagnosis in the course of T2DM coupled with appropriate glycaemic intervention, the better the outcome.

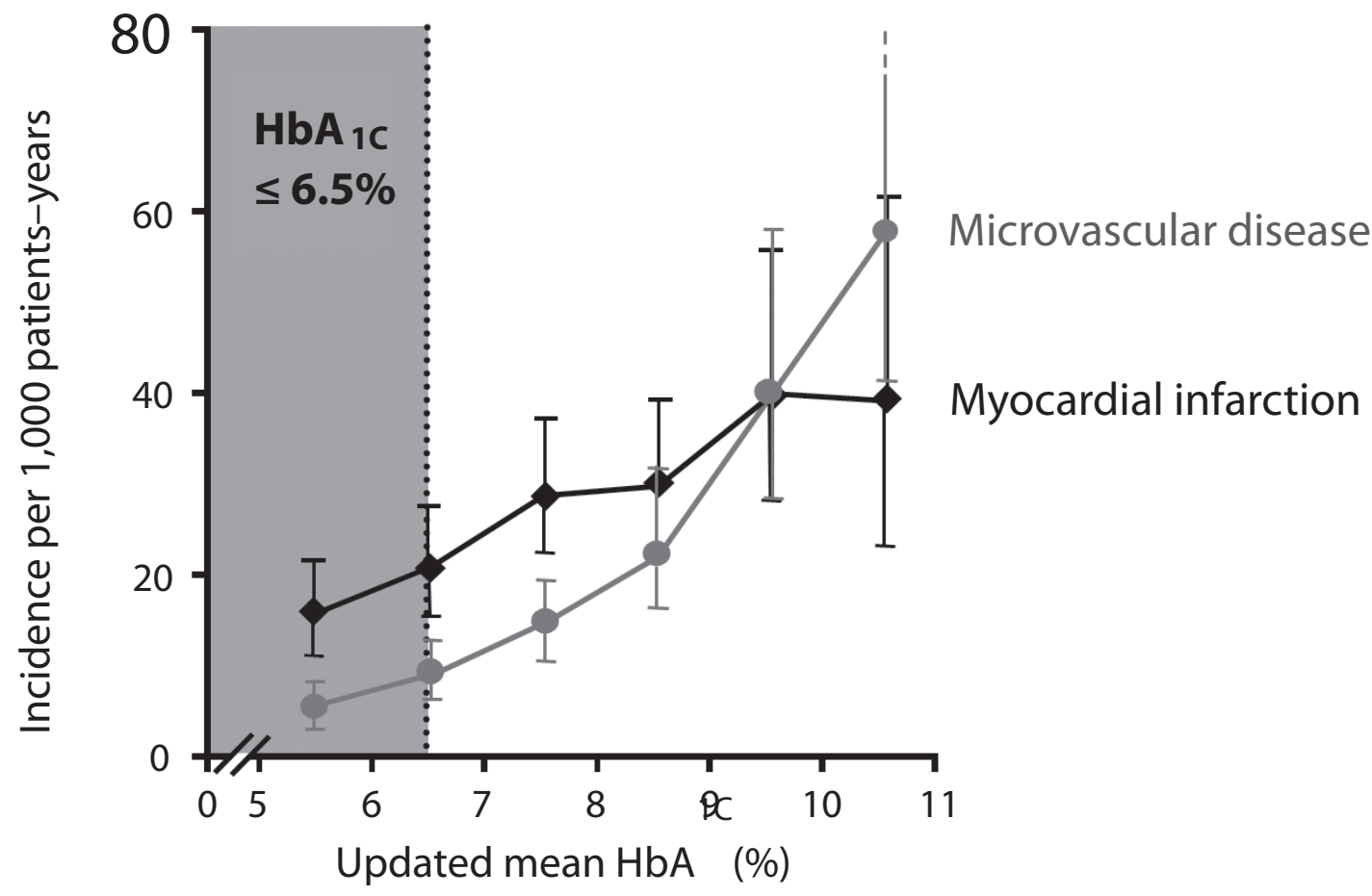

Study population: White, Asian Indian and Afro-Caribbean UKPDS patients $(n=4,585)$

Adjusted for age, sex and ethnic groupError bars $=95 \% \mathrm{Cl}$

Figure 3: Incidence of myocardial infarction (MI) and clinical complications in type 2 diabetes is significantly associated with glycaemia. Adapted from Stratton IM, et al. BMJ 2000; 321: 405-412. 
Analysis of the ACCORD study also confirmed that two subgroups did in fact benefit from intensive glucose control (2). The two subgroups comprised those with lower baseline $\mathrm{HbA} 1 \mathrm{c}<8.0 \%$ at recruitment as well as those without pre-existing cardiovascular disease.

Consistent with these findings, the VADT also showed that duration of diabetes had an impact on whether intensive glycaemic control produced cardiovascular (CV) benefits. Figure 4 shows that their data allowed them to develop an algorithm that suggested that CV benefit was found in those with diabetes duration of less than 15 years (9).

In fact, by the time the diagnosis of T2DM is made, we may have lost a lot of valuable time. Data from large epidemiological observational studies, such as the EPIC-Norfolk study, has noted that the relationship between $\mathrm{HbA} 1 \mathrm{c}$ and cardiovascular disease and all-cause mortality is continuous-starting from $\mathrm{HbA} 1 \mathrm{c}$ of $5.0 \%$ (10). This suggests that atherosclerotic vascular complications start well within the normal range of $\mathrm{HbA} 1 \mathrm{c}$, which is prior to recognition of diabetes.
Another well established fact is that individuals with glucose in the pre-diabetic range, i.e. impaired fasting glucose $(6.1-6.9 \mathrm{mmol} / \mathrm{L})$ and 2 hour post-OGTT 7.8-11.0 $\mathrm{mmol} / \mathrm{L})$ already have elevated risk of cardiovascular disease (CVD). Unfortunately, to date, there is no evidence that earlier interventions in individuals in the pre-diabetic phase will benefit with lower CV events .

\section{Glycaemic Intervention - Negative CV benefit? Too little, Too Short (duration)...}

To understand why the three recent CV outcome megatrials-i.e. ACCORD, ADVANCE and VADTwere negative, comparisons between patient characteristics entering these three trials and those of the UKPDS provide insights into the differences in outcomes. When these three trials are reviewed and juxtaposed to the UKPDS-it becomes retrospectively possible to understand that these trials were unlikely to show positive CV or macrovascular outcomes.

The UKPDS recruited newly diagnosed T2DM patients, who were younger, had less co-morbidities and

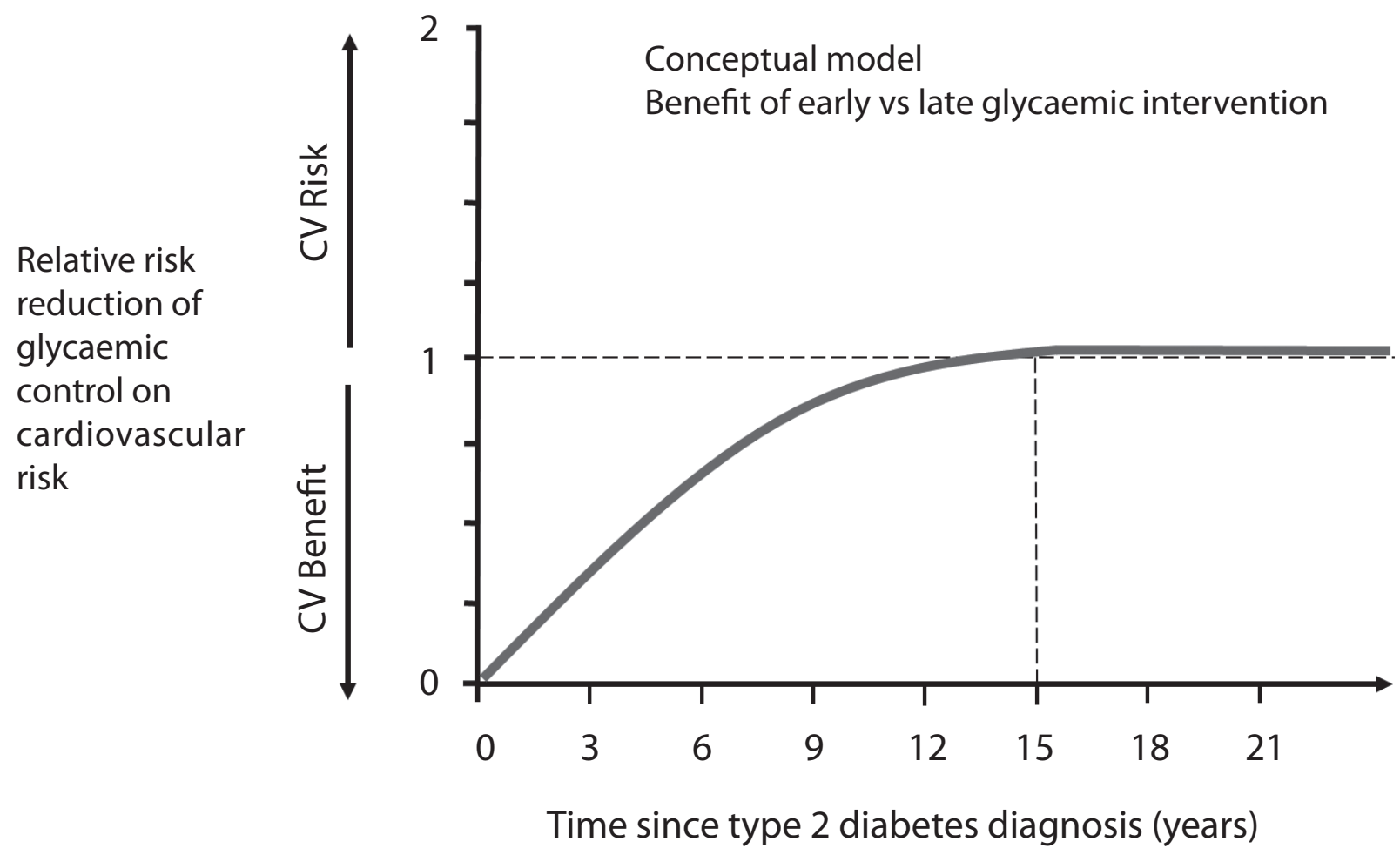

Figure 4: VADT - Relationship between time of intervention and the benefits of glycaemic control on macrovascular events. Adapted from VADT data presented at ADA June 2008. 


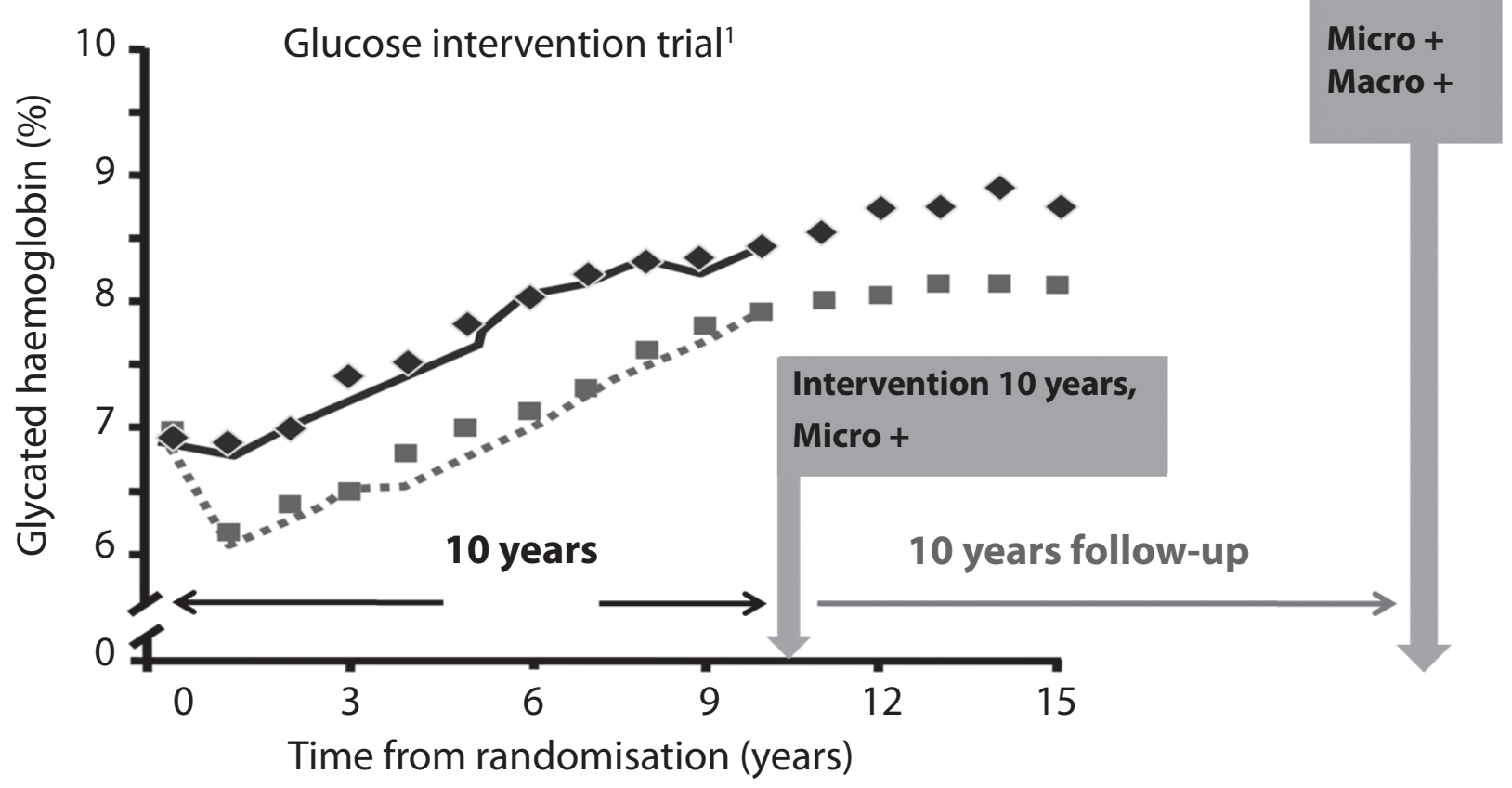

'UKPDS Group. Lancet 1998; 352: 837-853.

Figure 5a: UKPDS: Intervention Phase (10 years) followed by Post-trial monitoring (10 years)

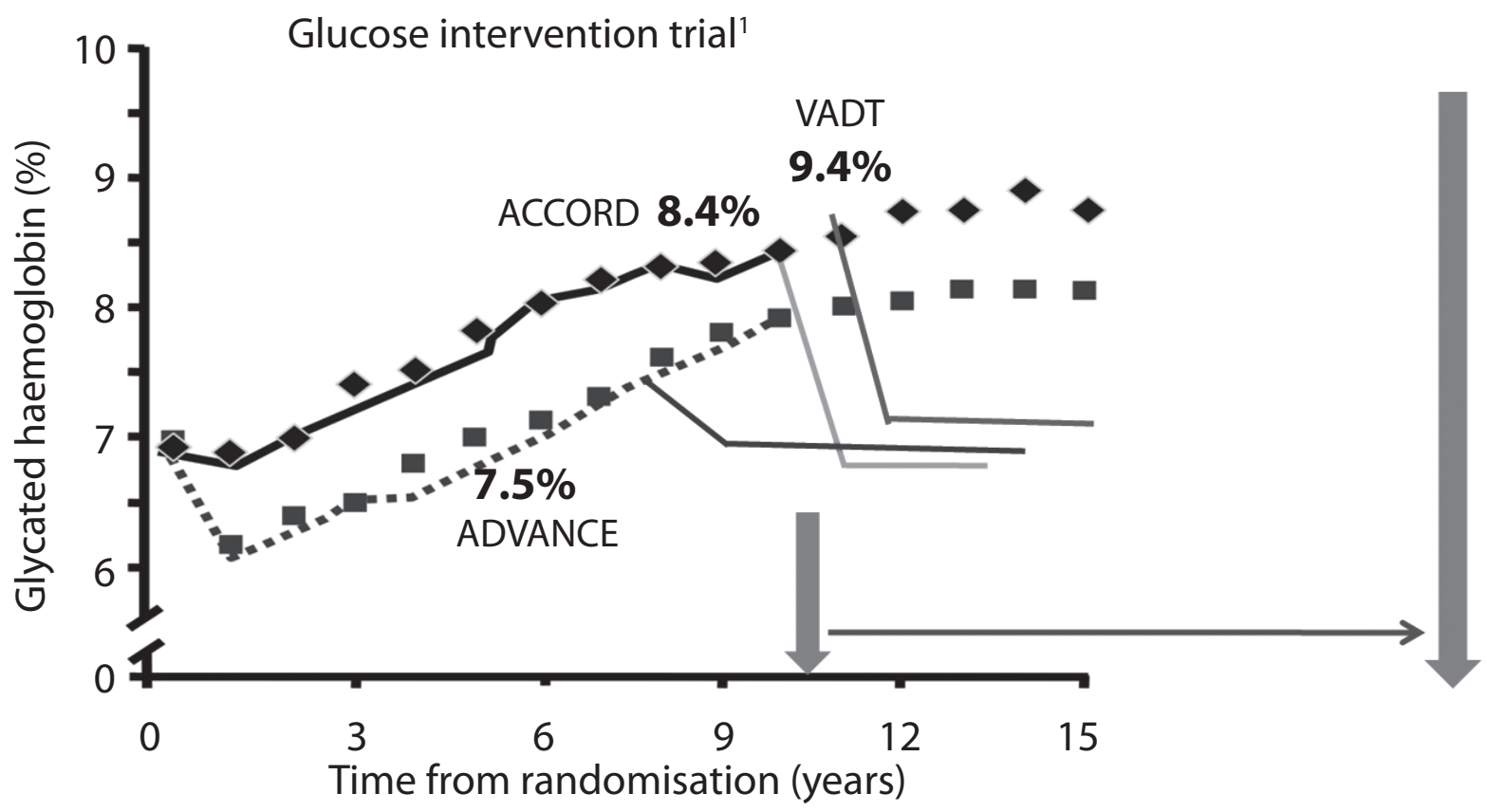

\section{LEGEND}

ADVANCE - baseline $\mathrm{HbA}_{1 \mathrm{c}} 7.5 \%$, duration T2DM 8 years, duration 5 years ACCORD - baseline $\mathrm{HbA}_{1 \mathrm{C}} 8.3 \%$, duration of T2DM 10 years, duration 3.5 years

VADT - baseline $\mathrm{HbA}_{1 c} 9.4 \%$, duration of T2DM 11.5 years, duration 6 years

'UKPDS Group. Lancet 1998; 352: 837-853.

Figure 5b: UKPDS with ACCORD, ADVANCE and VADT - Timelines of diabetes duration and differences in baseline HbA1c at recruitment 
lower baseline HbA1c. In Figure 5a, the UKPDS had a mean 10 year intervention phase followed by another 10 years of post-trial monitoring (PTM)-at which the macrovascular/CV benefit was eventually observed.

The three most recent trials recruited subjects who were older (60-66 years), had longer durations of diabetes (8-11.5 years), higher baseline HbA1c (7.5-9.4\%) and a high proportion of people with established CVD (32-40\%). In addition, Figure 5b shows that the duration of the interventions were short in comparison to the UKPDS, i.e. 3.5, 5 and 6 years respectively with no follow-up phase to observe $\mathrm{CV}$ benefits.

From Figure $5 b$, in retrospect, it is easy to understand that the three recent trials were unlikely to obtain positive CV outcomes by glucose intervention alone.

\section{HbA1c, How Low to Go-"Fly in the Ointment"}

Using the UKPDS data, 6.5\% was determined by the International Diabetes Federation as the optimal therapeutic $\mathrm{HbA} 1 \mathrm{c}$ target.

Unfortunately, the ACCORD trial data suggested that too aggressive glucose control was linked to the significant excess of sudden deaths. These deaths were largely presumed to be due to cardiovascular causes, in the Intensive arm (achieving $\mathrm{HbA} 1 \mathrm{c} 6.4 \%$ ) compared to their Standard arm (HbA1c 7.5\%). Since then, there have been extensive and detailed discussions and reviews attempting to understand the reasons for this unanticipated increase in CV mortality. Due to these unfavourable results, the American Diabetic Association (ADA) recommended that the target $\mathrm{HbA} 1 \mathrm{c}$ should be $7 \%$ (11).

Should all guidelines, therefore, adopt the ADA's recommendation? To answer that question, we are fortunate to have the results of the ADVANCE and VADT to help guide decision making.

The ADVANCE trial included a large proportion of Asian subjects-where Malaysia is proud to have been involved with the University Malaya Medical Centre (UMMC) being an investigational site. Results from this important trial are, therefore, relevant to the Asian region.
In the trial, similar patients to that of ACCORD and VADT were recruited. These patients were Type 2 diabetic individuals with very high CV risk, with up to $40 \%$ having established CVD at recruitment. Therefore, when the results were anticipated in June 2008 , there was an air of disappointment as the trial was forecast to be negative with regard to its CV impact. The overall objective of tight glucose control was achieved in the Intensive arm of the trial, which was $\mathrm{HbA} 1 \mathrm{c} 6.5 \%$ and the Standard arm achieved HbA1c 7.3\%. Despite the of lack of CV benefit when the final results of the ADVANCE trial were reported and published in June 2008 , the overall outcome was still viewed in a positive light. To an extent, it counteracted the negative impact of the excess sudden deaths in ACCORD.

The negative cardiovascular ADVANCE and VADT results together took on a different significance in that they showed that it was possible to get to glycaemic targets of $6.5 \%$ and $6.9 \%$ respectively without causing excess CV mortality.

The question, then, is: What should be the optimal glycaemic target? For this, the UKPDS analysis of the impact of the updated $\mathrm{HbA1C}$ (Figure 3) on complications should continue to be used to inform decision making (3). As such, the need to achieve good glucose control in patients with T2DM early remains a key goal.

\section{Glycaemic Control-"Do it Safely". Avoid Hypoglycaemia}

The debate surrounding the excess sudden deaths in the Intensive arm of the ACCORD continues. Although difficult to prove conclusively, the evidence points toward hypoglycaemia as one of the possible reasons for the sudden deaths. In a sub-analysis, it was recognised that individuals who had experienced any episode of hypoglycaemia had a higher CV mortality (12). Regardless of the intervention group, 2.9\% Intensive arm and $4.9 \%$ of Standard arm suffered CV mortality in those who had experienced hypoglycaemia. In comparison, the mortality rate among individuals without hypoglycaemia were $1.3 \%$ in the Intensive arm and $1.0 \%$ in the Standard arm.

Results from the VADT also showed that recent severe hypoglycaemia was 4.0 times more likely to predict CV death in that population. 
Other hypotheses that revolve around the excess CV mortality of the ACCORD suggest that too rapid reduction of $\mathrm{HbA} 1 \mathrm{c}$ and excessive weight gain may also have been negative influences.

\section{Multifactorial Interventions-"2-in-1" and "3- in-1" Trials}

T2DM clusters in individuals who have other CV risks, namely the Metabolic Syndrome. These include hypertension, dyslipidaemia (low HDL-cholesterol and high triglyceride) and android obesity. It is therefore, not surprising that a multifactorial approach involving aggressive management of all these CV risk factors have been confirmed to confer immediate benefit on CV outcomes that was not seen with pure glucose control alone.

Multifactorial approaches that had a "2-in-1" therapeutic goal (glucose and blood pressure) in the UKPDS and ADVANCE showed significant reductions in CV outcomes $(3,13)$. The "3-in-1" approach adopted by the STENO-2 (glucose + blood pressure + lipid lowering) had the best results with close to $53 \%$ reduction of CV mortality at the end of the eight year intervention phase (14). Figure 6 shows that after a further 5.5 years' observation, during which glycaemic control was no longer different, persistence in benefit of a $50 \%$ reduction in CV mortality or all cause mortality continued to be seen (15). This is again evidence of the Legacy or memory effect of previous good metabolic control.

The expected question that arises from the results of these multifactorial interventions is whether improvements in blood pressure and lipid control contribute to the legacy/memory effect. The answer comes from the UKPDS-10 year post-trial monitoring results that revealed that with a loss of blood pressure difference in the BP arm of the study. There was no further protection seen on both micro as well as macrovascular outcomes (16). Therefore, with regard to blood pressure control and its beneficial effects on complications, "What you see is what you get!".

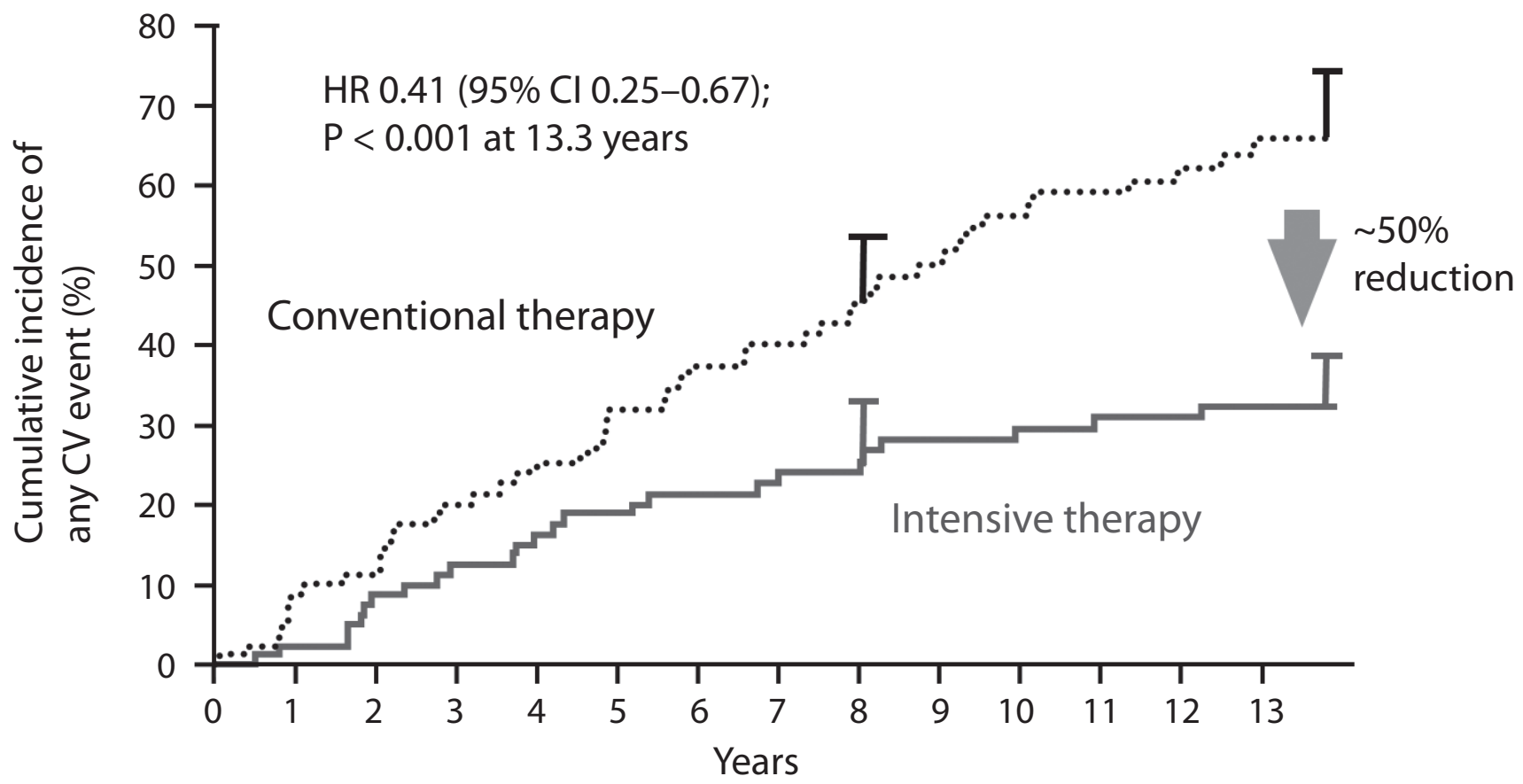

Figure 6: STENO 2: Multifactorial Intervention is Associated with Improved CV outcomes / Memory effect of prior Intervention shows persistence of benefit over another 5.5 years observation during which all parameters were no longer different ${ }^{14,15}$

Adapted from Gaede P, et al. N Engl J Med 2008; 358: 580-591. 


\section{Individualising Glycaemic Targets}

From the large evidence base gathered using the recent megatrials, it is reassuring that what clinicians have been intuitively practising has been correct, which is to Individualise glycaemic goals.

Recent revisions in most guidelines, including the 4th Malaysian Clinical Practice Guideline for the Management of Type 2 diabetes 2009, reflect this with recommendations for glycaemic targets to be adopted according to each individual patient's circumstanceswhich are;

- To be aggressive, to achieve $\mathrm{HbA} 1 \mathrm{c}<6.5 \%$, in those early in the course of their diabetes, without comorbidities, with an expected long and normal lifeexpectancy

- To be more flexible and allow higher $\mathrm{HbA} 1 \mathrm{c}$ levels in those with limited life-expectancy, history of severe hypoglycaemia, long duration of diabetes and comorbidities.

\section{Conclusions}

Macrovascular or CV benefits from good glycaemic control alone require many years of initial good control and then years - a decade more-before reaping the benefits of improved CV outcomes.

Multifactorial approaches involving aggressive management of blood pressure, lipid lowering. In addition to glycaemic control produces the CV benefits not seen with glucose control alone. Good blood pressure control does not have a legacy effect.

Given the evidence thus far, intensive glucose control remains an important and worthwhile goalespecially early in the course of the disease before complications (especially CVD) occur.

Glycaemic control-GET TO GOAL EARLY! GET TO GOAL SAFELY. Avoid hypoglycaemia!

\section{References}

1. UK Prospective Diabetes Study (UKPDS) Group. Intensive blood glucose control with sulphonylureas or insulin compared with conventional treatment and risk of complications in patients with Type 2 diabetes (UKPDS 33). Lancet 1998; 352: 837-853.

2. The Action to Control Cardiovascular Risk in Diabetes Study Group. Effects of intensive glucose lowering in Type 2 diabetes. N Eng J Med 2008; 358: 2545-2559.

3. The ADVANCE Collaborative Group. Intensive blood glucose control and vascular outcomes in patients with Type 2 diabetes. N Eng J Med 2008; 358: 25602572.

4. Duckworth W, Abraira C, Moritz T, et al. Glucose control and vascular complications in veterans with Type 2 diabetes. N Eng J Med 2009; 360: 129139.

5. Holman RR, Paul SK, Bethel MA, Mathews DR, Neil HA. 10 year follow-up of intensive glucose control in Type 2 diabetes. N Eng J Med 2008; 359(15): 15771588.

6. Nathan DM, Cleary PA, Backlund JY, Diabetes Control and Complications (DCCT/EDIC) Study Research group et al. Intensive diabetes treatment and cardiovascular disease in patients with Type 1 diabetes. N Eng J Med 2005; 353: 2643-2653.

7. Stratton IM, Adler AI, Neil HA, Matthews DR, Manley $\mathrm{SE}$, Cull CA, et al. Association of glycaemia with macrovascular and microvascular complications of type 2 diabetes (UKPDS 35): prospective observational study. BMJ 2000; 321: 405-412.

8. Colagiuri S, Cull CA, Holman RR for the UKPDS group. Are lower fasting plasma glucose Levels at diagnosis of Type 2 diabetes associated with improved outcomes? (UKPDS 61). Diabetes Care 2002; 25(8): 1410-1417.

9. Duckworth W (2008). VADT results. Available from http://webcasts.prous.com/netadmin/webcast_ viewer/Preview.aspx?type=0\&lid=3853. Accessed 20 Mar 2009.

10. Khaw KT, Wareham N, Bingham S, Luben R, Welch A, Day N. Association of hemoglobin A1c with cardiovascular disease and mortality in adults: The European prospective investigation into cancer in Norfolk. Ann Intern Med 2004; 141(6): 413-420. 
11. J Skyler, Bergenstal R, Bonow RO, Buse J, et al. Intensive glycaemic control and the prevention of cardiovascular events: implications of the ACCORD, ADVANCE and VADT trials: a position statement of the American Diabetes Association and a scientific statement of the American College of Cardiology Foundation and the American Heart Association. Diabetes Care 2009; 32: 187-192.

12. Byington RP for the ACCORD Study Group (2008). Relationship between post-randomisation hypoglycaemia and ACCORD mortality outcomes. Available from http://webcasts. prous.com/netadmin/webcast_viewer/Preview. aspx?type=0\&lid=3753. Accessed 20 Mar 2009.

13. Stratton IM, Cull CA, Adler Al, Mathews DR, Neil HA, Holman RR. Additive effects of glycaemia and blood pressure exposure on risk of complications in Type 2 diabetes: A prospective observational Study (UKPDS 75). Diabetologia 2006; 49: 17611769.
14. Gaede P, Vedel P, Larsen GV, Parving HH, Pedersen O. Multifactorial intervention and cardiovascular disease in patients with Type 2 diabetes. $N$ Eng $J$ Med 2003; 348: 383-393.

15. Gaede P, Lund-Andersen H, Parving HH, Pedersen O. Effect of Multifactorial Intervention on Mortality in Type 2 diabetes. N Eng J Med 2008; 358: 580-591.

16. Holman RR, Paul SK, Bethel MA, Neil HA, Mathews DR. Long-term follow-up after tight control of blood pressure in type 2 diabetes. N Eng J Med: 2008; 359: 1565-1576. 